\title{
Fabrication of Microporous Film and Microspheres Hybrids
}

\author{
Hossein Taherzadeh, Yasuko Shimoi, Kenji Ogino* \\ Graduate School of Bio-Applications and Systems Engineering, Tokyo University of Agriculture and Technology, \\ Koganei, Tokyo, Japan \\ Email: "kogino@cc.tuat.ac.jp
}

Received 7 March 2015; accepted 30 March 2015; published 1 April 2015

Copyright $@ 2015$ by authors and Scientific Research Publishing Inc.

This work is licensed under the Creative Commons Attribution International License (CC BY).

http://creativecommons.org/licenses/by/4.0/

(c) (i) Open Access

\begin{abstract}
Hybrids consisting of a microporous film and polymeric microspheres were fabricated via a simple method without a special apparatus. Highly ordered microporous polymer films with honeycomb structure were fabricated by a dissipative process utilizing amphiphilic poly(acrylic acid)block-polystyrene, which was synthesized by atom transfer radical polymerization followed by an acid-catalyzed ester cleavage reaction. In order to embed the microsphere efficiently, the dried microporous films should be soaked in methanol to alter the surface functionality and to improve the wettability of the film surface. The introduction of amino functionality to polystyrene microspheres by seeded polymerization of $\mathrm{N}, \mathrm{N}$-dimethylaminoethyl methacrylate drastically improved the embedding efficiency. The effect of open pore size was also investigated.
\end{abstract}

\section{Keywords}

\section{Amphiphilic Block Copolymer, Microporous Film, Hybrid, Microsphere, Surface Functionality}

\section{Introduction}

Highly ordered microporous polymer films with honeycomb structure have been fabricated by a simple nontemplate method utilizing various types of block copolymers [1]-[8]. Although rod-coil type poly(p-phenylene)$b$-polystyreneor star-shaped polystyrene has been used in a pioneer study [1], other types of block copolymers have been also utilized including T-shape copolymer [5] and amphiphilic block copolymers [7] [8]. It is recognized that the mechanism for the formation of honeycomb structure can be explained by dissipative processes, where controlled condensation and growth of water droplets on the cold surfaces resulting from solvent evaporation of polymer solutions may be used to create a patterned surface. Despite non-block copolymers such as

${ }^{*}$ Corresponding author. 
end-functionalized polymer [9], and amphiphilic random copolymers [10] [11], the utilization of block copolymer gives rise to another advantage because of self-assembly nature of block copolymers. Hayakawa et al. reported that using a specially designed block copolymer, resulting porous films had highly ordered hierarchical structures over multiple length scales from angstroms to micrometers [6]. Furthermore, the surface aggregation of selective component is expected [5].

Various applications of honeycomb films have been considered such as separation membranes [12], superhydrophobic materials [13], photonic or optoelectronic devices [14], cell-culturing substrates [15] [16], and micropatterning templates [10] [17] [18]. In our previous study, micropores were utilized as microreactors. Poly(aniline) dots were successfully fabricated via electropolymerization of aniline using a microporous film on indium tin oxide electrode as a template [7]. Yabu et al. prepared honeycomb-nanoparticles hybrid in order to obtain multiple-periodic structures [19]. A specially developed sliding apparatus was used for embedding the submicron polystyrene particles.

In this paper, a microporous film and polymeric microspheres hybrids were fabricated via a simple method without a special apparatus. Poly(acrylic acid)-block-polystyrene was used to fabricate a microporous film.

\section{Experimental}

\subsection{Synthesis of Poly(acrylic acid)-Block-Polystyrene}

Block copolymers are synthesized via atom-transfer-radical polymerization as a previously reported method [7]. Preparation of macroinitiator was carried out as follows. A 100-mL three necked flask equipped with a stirrer bar, a nitrogen inlet, and a rubber septum was charged with $\mathrm{CuBr}(0.74 \mathrm{~g}, 5.2 \mathrm{mmol}), \mathrm{CuBr}_{2}(0.058 \mathrm{~g}, 0.26$ mmol) under nitrogen. After the evacuation followed with backfilling of nitrogen, distilled $t$-butyl acrylate ( $t$-BA, $40 \mathrm{~g}, 0.31 \mathrm{~mol}$ ) was added via gas-tight syringe followed by N,N,N',N",N"'-pentamethyldiethylenetriamine (PMDETA, $2.17 \mathrm{~mL}, 10.4 \mathrm{mmol}$ ) and acetone $(5 \mathrm{~mL})$. After two freeze-pump-thaw cycles, $t$-butyl 2-bromopropionate $(1.72 \mathrm{~mL}, 10.4 \mathrm{mmol})$ was added and the mixture was allowed to stir at room temperature for $10 \mathrm{~min}$. The flask was then placed in a $60^{\circ} \mathrm{C}$ oil bath and the polymerization proceeded for $1 \mathrm{~h}$ under nitrogen atmosphere. THF solution of the reaction mixture was filtered with an $\mathrm{Al}_{2} \mathrm{O}_{3} / \mathrm{SiO}_{2}$ plug in order to remove the catalysts. After the concentration of solution, the polymer was precipitated into $50 \mathrm{vol} \%$ of methanol/ $\mathrm{H}_{2} \mathrm{O}$ mixture. The degree of polymerization was determined by the end group analysis based on ${ }^{1} \mathrm{H}-\mathrm{NMR}$ spectroscopy. Molecular weight and its distribution were estimated with GPC calibrated with polystyrene standards. Yield; 43\%, $D P=5$ (from NMR), $M \mathrm{n}=2.0 \times 10^{3}, M \mathrm{w} / M \mathrm{n}=1.3$.

A 50-mL three necked flask equipped with a stirrer bar, a nitrogen inlet, and a rubber septum was charged with poly $(t$-BA) $(0.801 \mathrm{~g}, 0.380 \mathrm{mmol}), \mathrm{CuBr}(54 \mathrm{mg}, 0.380 \mathrm{mmol})$ under nitrogen. After degas process as mentioned above, styrene (St) (19.75 g, $0.19 \mathrm{~mol})$ (500 equivalent to the macroinitiator) and PMDETA (0.33 g, $0.380 \mathrm{mmol}$ ) was added. Polymerization was carried out at $90^{\circ} \mathrm{C}$ for $24 \mathrm{~h}$. Similar procedures were utilized for purification. Yield: $42 \%, \mathrm{DP}=285$ (for styrene), $M \mathrm{n}=3.1 \times 10^{4}, M \mathrm{w} / M \mathrm{n}=1.7$.

A 50-mL three necked flask equipped with a stirrer bar, a nitrogen inlet, and a condenser was charged with $3.0 \mathrm{~g}$ of poly( $t$-BA)-block-poly(St), $p$-toluene sulfonic acid monohydrate $(0.33 \mathrm{~g}, 1.72 \mathrm{mmol})$, and $3.0 \mathrm{~mL}$ of dioxane under nitrogen atmosphere. The reaction mixture was refluxed for $10 \mathrm{~h}$ to eliminate $t$-butyl group. After cooling the solution was poured into excess amount of water to precipitate the product ( $2.8 \mathrm{~g})$.

\subsection{Synthesis of Microspheres (PSt and PSt-DM)}

Uniform sized polystyrene microsphere (PSt) with a diameter of $1.7 \mu \mathrm{m}$ was synthesized via dispersion polymerization in aqueous ethanol as previously reported [20]. Seed polymerization of N,N-dimethylaminoethyl methacrylate (DM) was conducted in the presence of ethylene glycol dimethacrylate (EDMA). PSt (1.0 g) dispersed into $15 \mathrm{~mL}$ of water was placed into $100-\mathrm{mL}$ three necked flask equipped with a mechanical stirrer, and a nitrogen inlet was charged. With gentle stirring, DM (0.970 g, $6.37 \mathrm{mmol})$, EDMA (30.2 mg, 0.152 mmol), 2,2'azobis(2-amidinopropane) dihydrochloride $(60.3 \mathrm{mg}, 0.222 \mathrm{mmol})$ were charged. Polymerization was carried out at $60^{\circ} \mathrm{C}$ for $12 \mathrm{~h}$.

\subsection{Fabrication of Microporous Films}

Carbon disulfide solution $(0.1-0.5 \mathrm{wt} \%, 50 \mu \mathrm{l})$ was drop-cast on a cleaned glass slide over an area of ca. 1.1 $\mathrm{cm}^{2}$ (circle with a diameter of $1.2 \mathrm{~cm}$ ) in a custom designed flow-hood $\left(640 \mathrm{~cm}^{3}\right)$ [7]. The humidity was kept at 
$75 \%$ at $25^{\circ} \mathrm{C}$ by bubbling the air through a reservoir containing saturated $\mathrm{NaCl}$ solution. The flow-rates were controlled to be $5-10 \mathrm{~L} / \mathrm{min}$ using a flow meter.

\subsection{Fabrication of Microporous Film and Microsphere Hybrid}

Microspheres (PSt or PS-DM) $(1.0 \mathrm{~g})$ were dispersed in $15 \mathrm{~mL}$ of distilled water. Microporous film on a glass slide was immersed in the slurry for $30 \mathrm{~min}$ with gentle stirring. After washing with water, the hybrid film was dried in vacuo.

\subsection{Characterization}

Resulting polymers were characterized with ${ }^{1} \mathrm{H}-\mathrm{NMR}$ (ECX 300, JEOL, Japan), IR (FT/IR-4100, JASCO, Japan), and GPC [20]. The surface features of microporous films, microspheres, and hybrid films were characterized by scanning electron microscope (SEM) (JSM-6510, JEOL, Japan).

\section{Results and Discussion}

\subsection{Preparation of Microsphere}

Successful preparation of PSt-DM was confirmed by solubility change and IR spectroscopy. PSt-DM showed partial solubility in chloroform due to the presence of PDM (insoluble in chloroform) and crosslinking with EDMA. Figure 1 shows IR spectra of PSt and PSt-DM. PSt-DM shows a stronger absorption at $1730 \mathrm{~cm}^{-1}$ assigned to $\mathrm{C}=\mathrm{O}$ stretching. Figure 2 shows SEM images of PSt (a) and PSt-DM (b). Even after seed polymerization, uniformity was kept, and both types of particle were found to have almost the same size $(1.7 \mu \mathrm{m})$.

\subsection{Fabrication of Microporous Films}

As described in a previous report [7], the resulting pore size was strongly dependent on the characteristics of the polymers and fabrication conditions. In this study, poly(acrylic acid)-block-poly(St) with high molecular weight was utilized in order to obtain robust microporous films. In Figure 3, the pore size is plotted against the flow rate for the different concentration of the block copolymer. With the increase of the flow rate, the resulting pore size increased. Lower initial polymer concentration afforded the larger pore size. In the initial stage of solvent evaporation, it is reported that the number of nuclei formed increases with the increase of polymer concentration and the amount of condensed water is almost the same each other, leading to the smaller pores [7]. Compared with a low molecular polymer (in [7]) $\left(M_{\mathrm{n}}=1.3 \times 10^{4}\right.$ from GPC, DPs of acrylic acid and styrene were 10, and 73, respectively), however, higher molecular weight polymer exhibited much smaller concentration and flow rate dependencies. This is probably due to the formation of "harder shell" on the surface of the high molecular weight polymer solution in the evaporation of solvent. It is reasonable that the shell retard the solvent evaporation resulting in the impediment of increase the amount of condensed water.

\subsection{Fabrication of Hybrid Films}

After drying a microporous film in vacuo for $24 \mathrm{~h}$, the film was immersed in the slurry of microspheres for 30 $\mathrm{min}$. In this process, however, almost no particles were embedded although the open diameter of pores (ca. $3 \mu \mathrm{m})$ was larger than the diameter of microsphere as shown in Figure 4. Although the electrostatic interaction between carboxyl group in the film and dimethylamino group in PSt-DM is expected, no significant difference was observed between two types of microspheres.

During the formation of pores, it is considered that water droplets were stabilized by the carboxyl groups. Collapse and coalescence of droplets were prevented by this stabilization. On other words, it is speculated that pore walls are covered with carboxyl groups just after the evaporation of water. However, it is considered that carboxyl groups go inside the film when it is exposed to air in order to lower the surface tension. As Kajiyama reported, the mobility of film surface is much higher than that of bulk [21], which makes it possible to alter the surface properties.

In order to put back the carboxyl groups to the surface, microporous films were soaked in methanol. Once the surface is rich in hydrophilic carboxyl groups, it is expected that wettability is improved, and electrostatic interaction is enhanced. Figure 5 shows SEM images of hybrids. It is revealed that microspheres were embedded in pores after immersion in methanol. In the case of PSt-DM, much more microspheres were fixed compared with 
PSt. These observations were attributed to improved wettability of film, and enhanced electrostatic interactions. As shown in this Figure, multi-number of microspheres were sometimes embedded in a single pore. In Figure 6, relationships between the ratio of pores with microsphere(s) and soaking time in methanol. After 10 min soaking, the number of embedded PSt-DM microsphere increased remarkably. As for PSt, the increase of the number of fixed microsphere was not observed even after 60 min soaking.

As mentioned in Section 3.2, the open pore size of microporous film can be controlled. Finally we investigated the relationship between the ratio of pores containing microsphere(s) and the open pore size. As the pore size increases, the ratio of pore containing microsphere increased as shown in Figure 7. Below $2.4 \mu \mathrm{m}$ of the pore diameter, the ratio of the pores with a single microsphere is higher compared with the pore with multinumber of microspheres. When the diameter was 2.4 or $2.7 \mu \mathrm{m}$, almost all pores where the microspheres were embedded contained multi-number of microspheres.

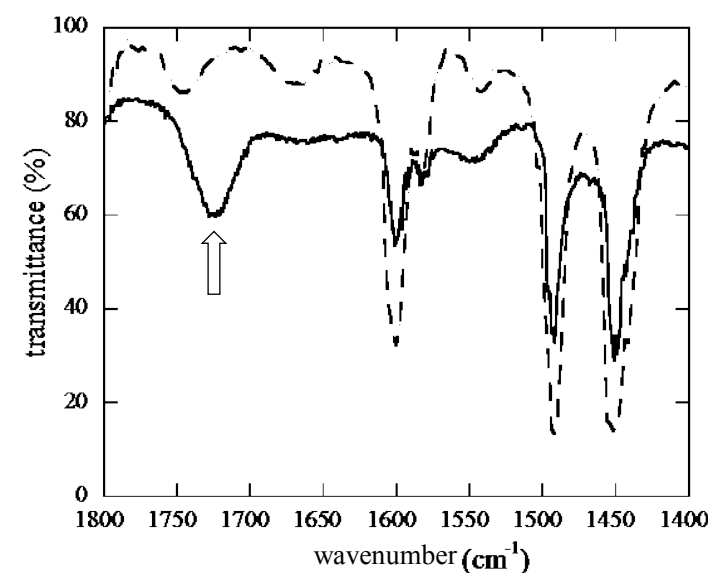

Figure 1. IR spectra of PSt and PSt-DM microspheres. PSt: broken line; PSt-DM: solid line.
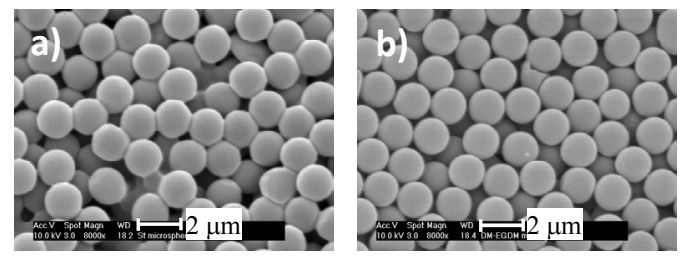

Figure 2. SEM images of PSt a) and PSt-DM b).

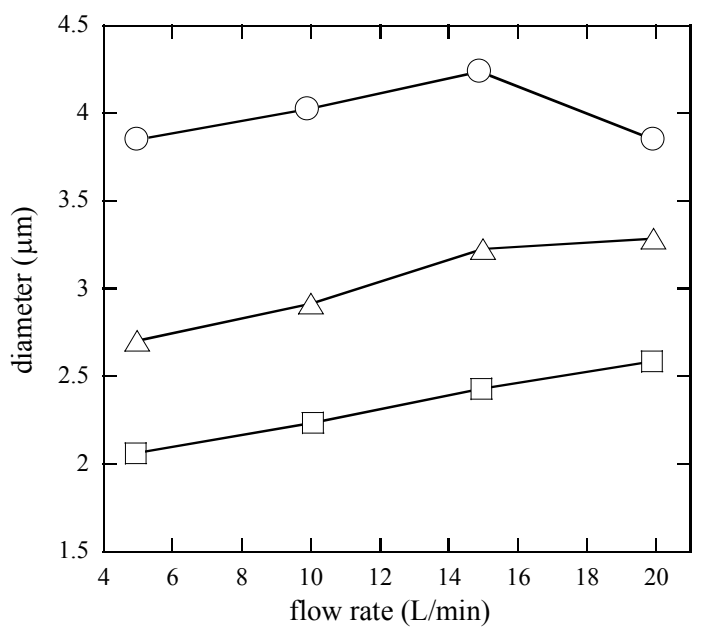

Figure 3. Flow rate dependence of pore size in the fabrication of microporous films. Initial concentration of polymer was $0.1 \mathrm{wt} \%$ (circle), $0.3 \mathrm{wt} \%$ (triangle), and $0.5 \mathrm{wt} \%$ (squre). 

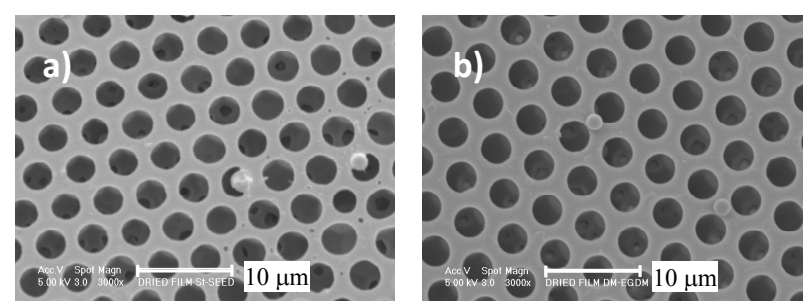

Figure 4. SEM images of microporous films after immersion in a slurry of PSt a) and PSt-DM b). Microporous film with 3 $\mu \mathrm{m}$ of open pore diameter was dried for $24 \mathrm{~h}$ in vacuo before immersion.
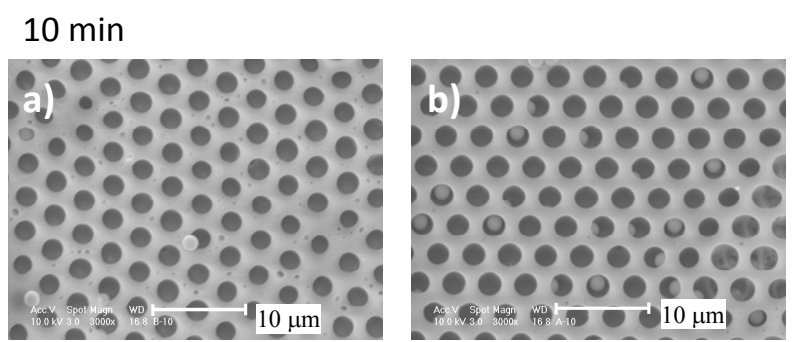

$20 \mathrm{~min}$
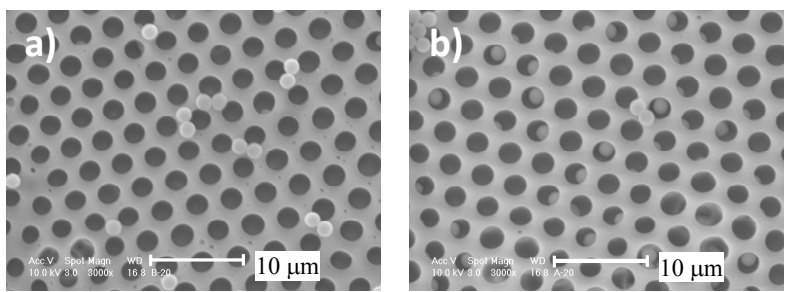

$30 \mathrm{~min}$
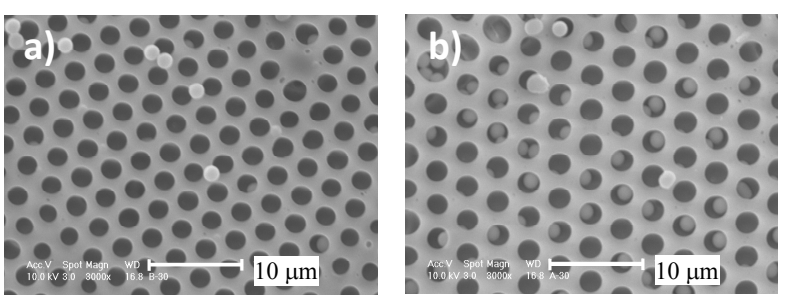

Figure 5. SEM images of microporous films after immersion in a slurry of PSt a) and PSt-DM b). Microporous film with $2.2 \mu \mathrm{m}$ of the open pore diameter was soaked in methanol for $10-30 \mathrm{~min}$ before immersion.

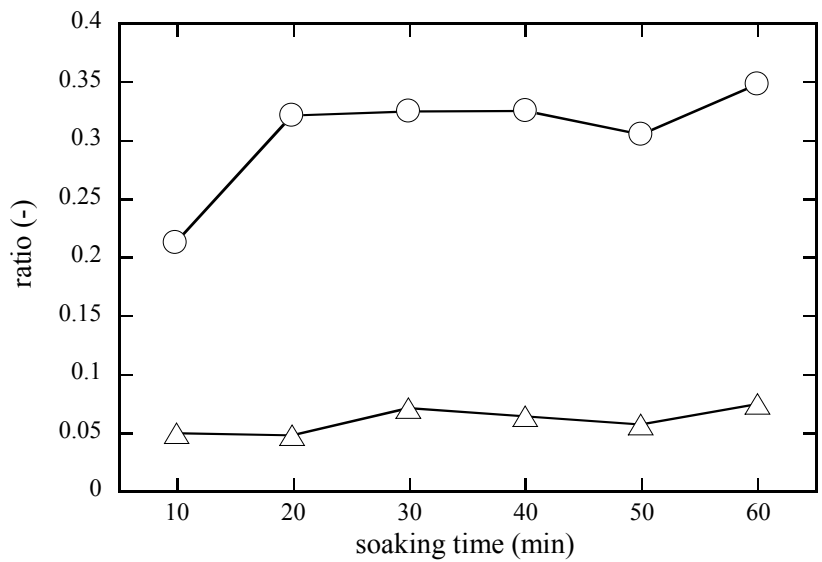

Figure 6. Relationship between the ratio of pores with microsphere(s) and soaking time in methanol. Circle: PSt-DM; blue triangle: PSt. 


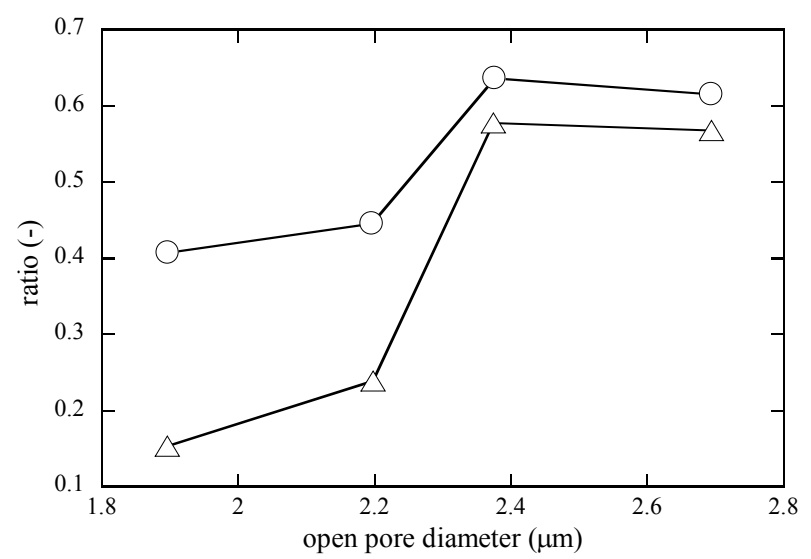

Figure 7. Relationship between the ratio of pores containing microsphere(s) and pore size. Circle: the ratio of pore with microsphere(s); triangle: the ratio of pore with multi-number of microspheres. Film was soaked in methanol for $20 \mathrm{~min}$.

\section{Conclusion}

Honeycomb films were successfully fabricated from the amphiphilic block copolymer, poly(acrylic acid)-blockpolystyrene) prepared via atom transfer radical polymerization followed by the acid catalyzed elimination reaction. After drying, the surface of the film was hydrophobic since carboxyl groups went inside the film in order to minimize the surface energy, and hybridization did not occur by immersing the film into slurry of polymer particles. By soaking the film in methanol, the wettability increased, and hybrid films were successfully obtained, where microspheres were embedded in the pore. The embedding efficiency of microspheres modified with amino groups was much higher than that of conventional polystyrene microspheres. Electrostatic interaction plays an important role for the hybridization. With the increase of open pore size, multi-numbers of microspheres were embedded in a single pore. It is noteworthy that our process utilizes no special apparatus for the fabrication of hybrids. It is expected that periodic arrangements of aggregates of microspheres can be fabricated using various combinations of pore size of microporous films and diameter of microspheres.

\section{References}

[1] Widawski, G., Rawiso, M. and François, B. (1994) Self-Organized Honeycomb Morphology of Star-Polymer Polystyrene Films. Nature, 369, 387-389. http://dx.doi.org/10.1038/369387a0

[2] François, B., Pitois, O. and François, J. (1995) Polymer Films with a Self-Organized Honeycomb Morphology. Advanced Materials, 7, 1041-1044. http://dx.doi.org/10.1002/adma.19950071217

[3] Jenekhe, S.A. and Chen, X.L. (1999) Self-Assembly of Ordered Microporous Materials from Rod-Coil Block Copolymers. Science, 283, 372-375. http://dx.doi.org/10.1126/science.283.5400.372

[4] de Boer, B., Stalmach, U., Nijland, H. and Hadziioannou, G. (2000) Microporous Honeycomb-Structured Films of Semiconducting Block Copolymers and Their Use as Patterned Templates. Advanced Materials, 12, 1581-1583. http://dx.doi.org/10.1002/1521-4095(200011)12:21<1581::AID-ADMA1581>3.0.CO;2-R

[5] Maeda, Y., Koshiyama, Y., Shimoi, Y., Yonezawa, N. and Ogino, K. (2004) Synthesis and Characterization of Luminescent and Hole Transporting Rod-Coil Polymers. Sen'i Gakkaishi, 60, 198-202. http://dx.doi.org/10.2115/fiber.60.198

[6] Hayakawa, T. and Horiuchi, S. (2003) From Angstroms to Micrometers: Self-Organized Hierarchical Structure within a Polymer Film. Angewandte Chemie International Edition, 42, 2285-2289. http://dx.doi.org/10.1002/anie.200219877

[7] Maeda, Y., Shimoi, Y. and Ogino, K. (2005) Fabrication of Microporous Films Utilizing Amphiphilic Block Copolymers and Their Use as Templates in Poly(aniline) Preparation. Polymer Bulletin, 53, 315-321. http://dx.doi.org/10.1007/s00289-005-0342-0

[8] Li, X.Y., Zhao, Q.L., Xu, T.T., Huang, J., Wei, L.H. and Ma, Z. (2014) Highly Ordered Microporous Polystyrene$b$-Poly(acrylic acid) Films: Study on the Influencing Factors in Their Fabrication via a Static Breath-Figure Method. European Polymer Journal, 50, 135-141. http://dx.doi.org/10.1016/j.eurpolymj.2013.10.017

[9] Srinivasarao, M., Collings, D., Philips, A. and Petel, S. (2001) Three-Dimensionally Ordered Array of Air Bubbles in a Polymer Film. Science, 292, 79-83. http://dx.doi.org/10.1126/science.1057887 
[10] Karthaus, O., Maruyama, N., Cieren, X., Shimomura, M., Hasegawa, H. and Hashimoto, T. (2000) Water-Assisted Formation of Micrometer-Size Honeycomb Patterns of Polymers. Langmuir, 16, 6071-6076. http://dx.doi.org/10.1021/la0001732

[11] Nishikawa, T., Ookura, R., Nishida, J., Arai, K., Hayashi, J., Kurono, N., Sawadaishi, T., Hara, M. and Shimomura, M. (2002) Fabrication of Honeycomb Film of an Amphiphilic Copolymer at the Air-Water Interface. Langmuir, 18, 57345740. http://dx.doi.org/10.1021/la011451f

[12] Tanaka, M., Takebayashi, M., Miyama, M., Nishida, J. and Shimomura, M. (2004) Design of Novel Biointerfaces (II). Fabrication of Self-Organized Porous Polymer Film with Highly Uniform Pores. Bio-Medical Materials and Engineering, 14, 439-446.

[13] Yabu, H., Takebayashi, M., Tanaka, M. and Shimomura, M. (2005) Superhydrophobic and Lipophobic Properties of Self-Organized Honeycomb and Pincushion Structures. Langmuir, 21, 3235-3237. http://dx.doi.org/10.1021/la050013w

[14] Saunders, A.E., Shah, P.S., Sigman, M.B., Hanrath, T., Hwang, H.S., Lim, K.T., Johnston, K.P. and Korgel, B.A. (2004) Inverse Opal Nanocrystals Superlattice Films. Nano Letters, 4, 1943-1948. http://dx.doi.org/10.1021/n1048846e

[15] Nishikawa, T., Nishida, J., Oookura, R., Nishimura, S., Wada, S., Karino, T. and Shimomura, M. (1999) Honeycomb-Patterned Thin Films of Amphiphilic Polymers as Cell Culture Substrates. Materials Science and Engineering: $C$, 8-9, 495-500.

[16] Hernandez-Guerrero, M., Min, E., Barner-Kowollik, C., Müller, A.H.E. and Stenzel, M.H. (2008) Grafting Thermoresponsive Polymersonto Honeycomb Structured Porous Films using the RAFT Process. Journal of Materials Chemistry, 18, 4718-4730. http://dx.doi.org/10.1039/b807495j

[17] Yabu, H. and Shimomura, M. (2005) Simple Fabrication of Micro Lens Arrays. Langmuir, 21, 1709-1711. http://dx.doi.org/10.1021/la046996z

[18] Li, L., Zhong, Y., Ma, C., Li, J., Chen, C., Zhang, A., Tang, D., Xie, S. and Ma, Z. (2009) Honeycomb-Patterned Hybrid Films and Their Template Applications via a Tunable Amphiphilic Block Polymer/Inorganic Precursor System. Chemistry of Materials, 21, 4977-4983. http://dx.doi.org/10.1021/cm902357m

[19] Yabu, H., Inoue, K. and Shimomura, M. (2006) Multiple-Periodic Structures of Self-Organized Honeycomb-Patterned Films and Polymer Nanoparticles Hybrids. Colloids Surface A: Physicochemical and Engineering Aspects, 284-285, 301-304. http://dx.doi.org/10.1016/j.colsurfa.2005.10.082

[20] Ogino, K., Sato, H., Tsuchiya, K., Suzuki, H. and Moriguchi, S. (1995) Synthesis of Monodisperse Macroreticular Styrene-Divinylbenzene Gel Particle and Control of its Pore Size. Journal of Chromatography A, 699, 59-69. http://dx.doi.org/10.1016/0021-9673(95)00031-H

[21] Kajiyama, C., Tanaka, K. and Takahara, A. (1998) Study of the Surface Glass Transition Behavior of Amorphous Polymer Film by Scanning-Force Microscopy and Surface Spectroscopy. Polymer, 39, 4665-4673. http://dx.doi.org/10.1016/S0032-3861(98)00049-4 